\title{
THE CORRELATION BETWEEN STUDENTS' ATTITUDES TOWARDS PEER REVIEWING WITH THEIR WRITING PROFICIENCY
}

\author{
Rully Raslina Novianti \\ STKIP SUBANG
}

\begin{abstract}
This research mainly discusses the correlation between students' attitudes towards peer reviewing with their writing proficiency to the $1^{\text {st }}$ year English Department students of STKIP Subang in Writing for General Purposes Subject. The population of this study is the $1^{\text {st }}$ semester English Department students on STKIP Subang. And there are 62 students as sample chosen through simple random sampling. There are two variables used in this study: the students' mid-term examination writing score and the result of students' responses in questionnaires. Correlational Design which is commonly used subset of Ex Post Facto Design is chosen in this study since it tends to look at the type and/or degree of relationship between two variables. The study finds that there is a positive correlation, although there is no significant correlation between students' attitudes toward peer reviewing with their writing proficiency. This study also divides students' attitudes of peer reviewing into three categories; students that like to do peer editing, both like and dislike it (neutral), and they that dislike it.
\end{abstract}

Key Words: student's attitudes, peer reviewing, writing proficiency,

\section{Introduction}

Writing is one of the four basic skills in learning language that should be acquired by students besides the three other skills; reading, listening, and speaking. Each skill must be learnt as well as possible. As a matter of fact, English Department students have to deal with certain subjects, one of them is writing subject. One of the objectives of writing subject is to let the students be able to write well in a whole aspect. And it is often the lecturers give writing assignment to fulfill their writing practice process.

Students' writing assignment must have feedback from the lecturer. Then a lot of manuscripts that should be graded with the time the lecturer spent often become an obstacle in writing subject. The time demands that the reading and editing of numerous student themes require are probably one reason teachers often refrain from assigning many themes to students, though there are no data to substantiate this association. One alternative to this dilemma would be the use of peer editing, a process whereby students edit and respond to each other's writing under the guidance of the teacher. With peer editing, the teacher is freed 
from the task of reading every essay written by every student and, therefore, assign more writing activities.

This research will try to investigate the correlation between peer editing with students' writing proficiency. Here, the peer editing is considered as one important aspect in students' writing progress.

Previous investigations have provided some support for peer editing. For example, some dissertation studies report that peer editing produces better writing than teacher editing; others showed no differences between peer and teacher. However, all these studies confounded peer editing with other instructional factors. Thus, the seemingly positive results found in the dissertation studies may actually have been due to other factors, such as the multiplication of writing experiences associated with peer editing in one study (Myra L. Karegianes: 1980).

\section{Statement of the Problem}

There are some problems found in writing classes as follow:

Lecturers often have an obstacle in evaluating students' writing tasks and giving feedback since these often consume a lot of time. Students are often difficult to find out their mistakes in writing.

\section{Purpose of the Study}

The purposes of this study are:

- to find out the correlation between students' attitudes toward Peer Editing with their writing proficiency;

- to find out the students' attitudes toward Peer Editing that have been done in Writing for General Purposes class.

\section{Research Questions}

- Is there any correlation between students' attitudes toward Peer Editing with their writing proficiency?

- What are the students' attitudes toward Peer Editing that had been done in Writing for General Purpose's class?

\section{Hypothesis}

The following hypothesis is used in the calculation of t-test to find out whether there is a correlation between students' responses toward Peer Editing with their writing proficiency: 
- H0 : There is no correlation between students' responses toward Peer Editing with their writing proficiency.

- H1 : There is a correlation between students' responses toward Peer Editing with their writing proficiency.

\section{Definition of Terms}

To avoid misinterpretation and to make the terms stated clear in this research, the terms are clarified as followed.

Peer Editing: A learning strategy in which a student evaluates another student's work and provides feedback.

Students' responses: Response given by students clarify whether they are like, neutral or even dislike toward peer editing activities.

Writing proficiency: Proficiency based on the students' midterm examination score.

\section{Delimitation and Limitation of the Study}

This study is only limited to find out the correlation between students' responses toward Peer Editing with their writing proficiency and analyze the results of students' responses toward peer editing.

\section{Significance of the Study}

This study is likely to have implication to the improvement strategies in teaching-learning process of writing subject.

\section{Literature Review}

There are several studies which discuss the effect of peer editing on writing proficiency. The studies imply that there are some supports for peer editing, while there are also some that show the ineffectiveness of it. Although there is no prior study specifically elaborating about the correlation yet, but this study will try to find the correlation between the students' attitudes toward it with their writing proficiency. Hence it is important in this study to affirm the correlation of students' responses of peer editing with their writing proficiency as the effect of peer editing.

Karegianes (2008) investigated the effects of a highly-structured peer editing treatment on the essay-writing proficiency of low-achieving tenth grade students. With the effects of subject sex, pretreatment essay proficiency, and reading level controlled statistically, the peer edit group had significantly higher $(\mathrm{p}<.05)$ writing proficiency (as rated by trained 
independent judges) than did students whose essays were edited by teachers. The findings have implications, both for time spent by teachers grading essays as well as for use of peer editing as a potentially effective instructional technique in the teaching of writing proficiency.

Another study is investigated by Jefferson (2002) toward Effects of Editorial Peer Review (A Systematic Review). From nineteen studies investigated, he found nine studies considered the effects of concealing reviewer/author identity. Four studies suggested that concealing reviewer or author identity affected review quality (mostly positively); however, methodological limitations make their findings ambiguous, and other studies' results were either negative or inconclusive. One study suggested that a statistical checklist can improve report quality, but another failed to find an effect of publishing another checklist. One study found no evidence that training referees improves performance and another showed increased interrater reliability; both used open designs, making interpretation difficult. Two studies of how journals communicate with reviewers did not demonstrate any effect on review quality. One study failed to show reviewer bias, but the findings may not be generalizable. One nonrandomized study compared the quality of articles published in peer-reviewed vs. other journals. Two studies showed that editorial processes make articles more readable and improve the quality of reporting, but the findings may have limited generalizability to other journals.

Jefferson (2002) in Measuring the Quality of Editorial Peer Review identified outcome measures used to assess editorial peer review as performed by biomedical journals, he analyzed studies identified from 2 systematic reviews that measured the effects of editorial peer review on the quality of the output (i.e., published articles) or of the process itself (e.g., reviewers' comments).

The results of the study showed ten studies used a variety of instruments to assess the quality of articles that had undergone peer review. Only 1, nonrandomized study compared the quality of articles published in peer-reviewed and non-peer-reviewed journals. The others measured the effects of variations in the peer-review process or used a before-and-after design to measure the effects of standard peer review on accepted articles. Eighteen studies measured the quality of reviewers' reports under different conditions such as blinding or after training. One study compared the time to cost of different review processes.

It could be concluded whether the previous investigations have provided some support for peer editing (Karegian: 2008) or even showed the uncertain effects of it and remaining almost impossible to assess or improve its effectiveness (Jefferson: 2002), it is important to 
investigate the correlation of the students' responses on peer editing with their writing proficiency.

Peer editing/reviewing is a learning strategy in which a student evaluates another student's work and provides feedback. This is a standard strategy used in writing courses across the curriculum. However, instituting peer review in a course requires forethought and organization, since without careful planning the exercise can become meaningless for students and frustrating for instructors. When it is well done it benefits both students and faculty; it can help develop critical thinking and writing skills and make your marking easier.

Peer editing generally refers to commenting on a paper's organization, tone, format, flow, grammar, punctuation, and even content. When reviewing a paper for content, students assess whether there is a well-defined thesis statement, the depth to which the topic was adequately covered, assumptions and biases, and the strength of the paper's argument. In their written responses, peer editors must give constructive and honest commentary that acknowledges a paper's strengths, suggests possible improvements or identifies problem areas, and provides grammar, style, referencing, or other mechanical corrections. Authors become aware that they must write so that their readers can understand their argument and that they are responsible for accepting or rejecting advice or alternative points of view (Anonymous: 2008)

The use of peers to assess the work of fellow scientists goes back at least 200 years (Kronick DA.: 1990). It is usually assumed to raise the quality of the end product and to provide a mechanism for rational, fair, and objective decision making. Despite the fact that peer review has such a long history and is so well established, research into its effects is a recent phenomenon. However, the body of original research on the effects of peer review has been growing, and systematic review and synthesis may now be possible (Overbeke J.: 1999). This review assesses the effects of processes undertaken as part of editorial peer review of original research studies submitted for paper or electronic publication in biomedical journals.

Peer review in scientific journals is a widely used and well-established method to assess research reports. Peer review has two principal functions: filtering out incorrect or inadequate work and improving the accuracy and clarity of published reports (Jefferson T, Alderson P, Wager E, and Davidoff F.: 2002). As will be stated again in the updated Cochrane review on peer review, little is yet known about the effectiveness of the peer review process (Jefferson TO, Alderson P, Davidoff F, and Wager E.: 2005). This is due in part to the fact that assessment of the peer review process is predominantly behavioral science. Only recently has research begun on the effects and shortcomings of peer review. Research has shown that 
readers of the Dutch Journal of Medicine believe that an article's quality is improved by peer review (Pierie JP, Walvoort HC, Overbeke AJ.: 1996).

According to Ann Mc Neal (2008) when students do intensive editing and rewriting, they learn a great deal about both content and written expression, but the process can take tremendous amounts of faculty time. Peer-editing is one way to engage students more actively in the editing process, but there can be a problem that beginning students don't know enough to be able to offer good suggestions to one another. Beachy (1992) suggests the use of guideline sheets to aid students in their peer-editing.

Since the peer editing is considered as one important aspect in students' writing progress, this research will try to investigate the correlation between peer editing with students' writing proficiency.

\section{Methods}

\section{Research Design}

Correlational Design which is commonly used subset of Ex Post Facto Design is chosen in this study since it tends to look at the type and/or degree of relationship between two variables. In correlational design, a group of students may give us data on two different variables (Farhady: 1982).

\section{Data Collection}

Population and Sample

Sugiono (2009) defines population as a generalization area of object or subject that fulfills certain requirements to be studied and then concluded by researchers. Meanwhile sample is defined as part of a population's amount and characteristics. The population of this research is the $1^{\text {st }}$ semester of English Department students on STKIP Subang. And there are 62 students as sample chosen through simple random sampling.

Instrumentations and Materials

The instruments of this study are students' compositions and questionnaire to record students' responses on peer editing activity. In the writing class, students were given tasks to write a composition based on certain topic related to the material discussed in each session. Then in the next session, they should exchange their compositions to their friends to be reviewed. But beforehand lecturer must have explained about the procedure for reviewing composition. 


\section{Variables in the Study}

There are two variables used in this study: the students' mid-term examination writing score and the result of students' attitudes in questionnaires.

\section{Procedures}

This study was conducted in 5 weeks from October $19^{\text {th }}$ to $21^{\text {st }}$ November 2009. Previously the lecturer assigned the students to write a narrative composition and surely they were given the criteria for a good composition. Then in the first week of the research the lecturer explained about peer reviewing; what it is, how it is conducted and what the purposes are. Next the students were paired by the lecturer to exchange and start reviewing their pair's composition, they read and marked up one another's papers, filled out the feedback sheets, comment on grammar, punctuation, topic sentences, etc. and discussed the revisions needed. Afterwards they handed in their works to the lecturer.

The second week, the lecturer still assigned the students to write another composition and do the same task by reviewing their pair's composition. And the results of reviewed compositions were evaluated by the lecturer to know whether the students had reviewed their pair's composition correctly or not.

In the third week the lecturer spread questionnaires to clarify their responses and opinions of the reviewing activities. Then in the next week, the mid-term examination was held. And at the last week, the score of students' writing midterm examination were collected, and the questionnaire results were started to be analyzed.

\section{Data Analysis}

There were some steps taken to analyze the data as followed:

- determining the students' score in their writing examination;

- determining the students' attitude toward peer reviewing from the questionnaire by Likert-type scale- a scale used to measure how much of the variable to attribute to a person, text or object (Hatch: 1991). It can show the degree of students attitudes' toward peer reviewing by using the scale of 3 (like), 2 (neutral), and 1 (dislike).

- analyzing the correlation of X (students' attitudes toward peer reviewing) and Y (the students' score of midterm exam) using the correlation coefficient (called the Pearson product moment correlation), with the formula:

$$
r=\sqrt{N\left(\sum X Y\right)-\left(\sum X\right)\left(\sum Y\right)}
$$




\section{Discussion and Data Analysis}

The Correlation between Students' Attitude with Their Writing Scores

There are certain steps to find out the correlation between students attitudes with their writing scores. Hence it should be found the correlation coefficient, sometimes called the Pearson product-moment correlation; $r$ is the symbol for the Pearson correlation coefficient.

Because $\quad r=\sqrt{\frac{N\left(\sum X Y\right)-\left(\sum X\right)\left(\sum Y\right)}{\left[N \sum X^{2}-\left(\sum X\right)^{2}\right]\left[N \sum Y^{2}-\left(\sum Y\right)^{2}\right]}}$

the formula looks complicated, it can be computed in five separate steps, as in Hatch \& Lazaraton (1991: 433);

List the scores for each student (S) in parallel columns on a data sheet. (students' attitudes as $\mathrm{X}$ or as independent variable and students' scores as $\mathrm{Y}$ or as dependent variable).

Square each score and enter these values in the column labeled X2 and Y2

Multiply the scores (X x Y) and enter this value in the XY column.

Add the values in each column.

Insert the values in the formula.

The information from steps 1 through 4 is entered in the appendix. Since the values can be found in the chart (appendix), hence the formula:

$$
\begin{aligned}
& r=\sqrt[62(10780)-(157)(4246)]{\left[62 \times 433-(157)^{2}\right]\left[62.292248-(4246)^{2}\right]} \\
& r=\longdiv { 1 7 3 8 } \\
& r=0.123
\end{aligned}
$$

The final value of $r=0.123$ shows a positive correlation. The closer the $r$ value is to 1 , the stronger the relationship between the variables (Hatch \& Lazaraton, 1991: 435). It means the $r$ obs. (0.123) shows that it does not look like a very strong relationship.

Then to determine the statistical significance of the correlation, the r.obs needs to be compared with the critical value of Pearson product-moment correlation coefficient. It is found that the $r$ critical for $\mathrm{N}=62$ with the 0.05 level of significance and using 2-tailed test, since the $d f=n-2$ is 60 , so $r$-critical of 60 is 0.250 . It means $r$-obs. $(0.123)$ is less than $r$ critical (0.250), so it also means that $\mathrm{H} 0$ is accepted. And it is clearly found that there is no 
significant correlation between students' attitudes toward peer reviewing with their writing proficiency.

\section{Students Attitudes toward Peer Reviewing}

Categorization of students' attitudes toward peer reviewing

The Students' attitudes were categorized into three types;

The first category is students who considered the importance of peer editing and they liked to do Peer Editing. They believed that peer editing will improve their writing skill. And they did enjoy doing it.

The second category is they that considered the importance of it and they also both liked and also disliked to do peer editing or in other words they are neutral. They often liked or even disliked it depended on the difficulty degree of the text/composition that should be reviewed. They often enjoyed it if the composition was easily understood. But it would be a trouble if the text was rather complicated or difficult to be understood. The difficulties here might be caused of lack of knowledge of vocabulary or grammarian text of either the writer or the reviewer.

The third category is students who considered the importance of it but they disliked to do it caused of certain reasons; they didn't know what to do, they didn't feel confident to review their friends' composition, lack of grammar and punctuation knowledge, and other reasons.

The participants of this study were 62 students of $1^{\text {st }}$ semester in STKIP Subang majoring in English Department. And the students' attitudes were divided into three categories as explained above.

\section{The Fisrt Category (Like Peer Editing)}

There were 43 students could be categorized into the $1^{\text {st }}$ category. They gave some reasons why they believed peer editing was very important and useful. Some of the reasons are:

Peer editing may let us practice writing better.

It will add our knowledge in writing proficiency.

It will help us to be aware of our mistake in writing hence e can correct our mistake.

It will help us to be aware more about the use of punctuation, grammar, capitalization, etc.

It can motivate us to write better.

It helps us to test ourselves in writing. 
It's good for appreciating our work.

It's good to build close and better relationships one to each other.

It may remind us to write carefully and pay attention to the grammar, punctuation, and capitalization.

We may know our friends' writing ability.

We can compare our manuscript with others.

We can give comments to our friends work for them for being better.

\section{The Second Category (Neutral)}

There were 9 students could be categorized into the $3^{\text {rd }}$ category. They gave some reasons why they believed peer editing was important but they either liked or disliked doing peer editing. Some of the reasons are:

They enjoyed it but they often confused.

It depended on the text difficulties. If there were too many difficult/strange sentences, it would be hard for them.

They enjoyed it but they were afraid of doing mistake in reviewing the manuscripts.

It was not always an enjoyable one, because they didn't understand all the instructions.

Sometimes they disliked it, because it made them confused.

\section{The Third Category (Dislike Peer Editing)}

There were 10 students could be categorized into the $2^{\text {nd }}$ category. They gave some reasons why they believed peer editing was important but they did not like or enjoy doing peer editing. Some of the reasons are:

It was caused they felt afraid of doing mistake in reviewing their friends work.

Peer editing is very difficult.

They don't know what should be corrected.

They don't understand what should be edited.

They can't carefully review their friends' manuscript.

Some of them didn't feel confidence about their manuscript.

They didn't feel free in writing, as if they are confined in writing.

Because we must have good skills to review the manuscript.

They didn't understand their friends' manuscript.

Because they didn't understand the lecturer's instruction.

They were doubt whether their corrections were right or wrong. 


\section{The Distribution of Students' Attitudes and Their Writing Proficiency}

The students writing skill were categorized into three categories; high, middle, and low. The categories were based on their writing assignments' scores and also the score of their Writing Midterm examination.

\begin{tabular}{|l|l|l|}
\hline $\begin{array}{l}\text { The range of the writing } \\
\text { scores:CATEGORIES }\end{array}$ & GRADE & RANGE \\
\hline High & A & $\mathbf{8 1}-\mathbf{1 0 0}$ \\
\hline Middle & B & $\mathbf{6 6}-\mathbf{8 0}$ \\
\hline Low & C & $>\mathbf{6 6}$ \\
\hline
\end{tabular}

\section{$1^{\text {st }}$ category (Like Peer Editing)}

$70 \%$ of all participants (43 students) were categorized into the $1^{\text {st }}$ category. And this category was classified according to their Mid Term Exam Scores as we can look at the table below:

\begin{tabular}{|l|l|l|l|}
\hline CATEGORIES & GRADE & SUM of STUDENTS & RATE \\
\hline High & A & 1 & $2 \%$ \\
\hline Middle & B & 24 & $57 \%$ \\
\hline Low & C & 17 & $41 \%$ \\
\hline
\end{tabular}

\section{$2^{\text {nd }}$ category (Neutral)}

$14 \%$ of all participants ( 9 students) were categorized into the $3^{\text {rd }}$ category. This category was classified according to their Mid Term Exam Scores as we can look at the table below:

\begin{tabular}{|l|l|l|l|}
\hline CATEGORIES & GRADE & SUM of STUDENTS & RATE \\
\hline High & A & 0 & $0 \%$ \\
\hline Middle & B & 8 & $89 \%$ \\
\hline Low & C & 1 & $11 \%$ \\
\hline
\end{tabular}

\section{$3^{\text {rd }}$ category (Dislike Peer Editing)}

$16 \%$ of all participants (10 students) were categorized into the $3^{\text {rd }}$ category. This category was classified according to their Mid Term Exam Scores as we can look at the table below:

\begin{tabular}{|l|c|c|c|}
\hline CATEGORIES & GRADE & SUM & of \\
STUDENTS & RATE \\
\hline High & A & 0 & $0 \%$ \\
\hline Middle & B & 7 & $70 \%$ \\
\hline Low & C & 3 & $30 \%$ \\
\hline
\end{tabular}

It can be seen from the data findings above that each category has their own dispositions. 
The $1^{\text {st }}$ category - the students that liked to do peer editing- showed that they were divided into three categories based on their writing scores. It was found that there was only 2 $\%$ of them had High Grade. And 57\% of them were in Middle Grade. Then $41 \%$ of them got the Low Grade in their writing score.

The $2^{\text {nd }}$ category - the students that either liked or disliked (neutral) to do peer editingshowed that they were divided into two categories based on their writing scores. It was found that there was only $89 \%$ of them had Middle Grade. Then $11 \%$ of them got the Low Grade in their writing score.

The $3^{\text {rd }}$ category - the students that disliked to do peer editing- showed that they were divided into two categories based on their writing scores. It was found that there was only 70 $\%$ of them had Middle Grade. Then 30\% of them got the Low Grade in their writing score.

So, it can be seen obviously there was correlation between the students' attitudes and their writing scores even though it was not really significant. The students that liked to do peer editing were only $2 \%$ of them that got good score (High Grade). While there was no student that disliked peer editing got the High Grade, neither did the $2^{\text {nd }}$ category students.

Then there were $57 \%$ students in the $1^{\text {st }}$ category were in the Middle Grade. $70 \%$ students of the $2^{\text {nd }}$ category, and $89 \%$ of the $3^{\text {rd }}$ category were in the Middle Grade. And there were $41 \%$ students in the $1^{\text {st }}$ category, $30 \%$ students of the $2^{\text {nd }}$ category $11 \%$ of the $3^{\text {rd }}$ category were in the Low Grade.

\section{Conclusions and Suggestions}

This study provides the correlation between students' attitudes toward peer reviewing with their writing proficiency. It is found in this study that the final value of $r$ shows a positive correlation, although there is no significant correlation between students' attitudes toward peer reviewing with their writing proficiency.

The study also shows three categories of students attitudes toward peer reviewing that have been done in the subject of Writing for General Purpose's class. The categories are; $1^{\text {st }}$ category is students who considered the importance of peer reviewing and they like to do it. The $2^{\text {nd }}$ category is they that considered the importance of it and they also both liked and also disliked to do peer editing (neutral). The $3^{\text {rd }}$ category is students who considered the importance of it but they disliked to do it. Later on each category also should be classified 
based on their writing scores. And each score must be categorized into; high, middle, and low.

In conclusion, this study has shown a positive correlation, although there is no significant correlation between students' attitudes toward peer reviewing with their writing proficiency. There would be several aspects that need attention more in later on study related to this study, whether about the application and practice of peer reviewing itself or even the time of research allocation. The longer the time would probably give significant influence and correlation.

In other words, it is suggested that this exploration on the research findings will certainly require follow up researches that simply will provide more accurate information on the students' attitudes toward peer reviewing with their writing proficiency.

\section{References:}

Annemieke P. Landkroon, MD, Anne Margriet Euser, Hans Veeken, MD, PhD, Wimpeter Hart, MD, PhD and A. John P. M. Overbeke, MD, PhD. "Quality Assessment of Reviewers' Reports Using a Simple Instrument." Nederlands Tijdschrift voor Geneeskunde (Dutch Journal of Medicine), the Netherlands; and 2Department of Epidemiology, Leiden University Medical Center, the Netherlands. http://www.greenjournal.org/cgi/content/full/108/4/979

Anonymous. 2008. Peer Review \& Editing. University of Guelph Library Guelph, ON, $\begin{array}{lllll}\text { Canada } & \text { N1G. } & 7 & \text { November } & 2008 .\end{array}$ http:[//www.lib.uoguelph.ca/assistance/writing_services/faculty_\&_TAs/resources_to_su pport_student.../peer_review.cfm - 22k -]

Beachy, C.J. 1992. "Enhancing writing through cooperative peer editing" in N. Davidson and T. Worsham (eds.) Enhancing Thinking through Cooperative Learning. New York: Teachers. College Press. pp. 209-220.

Farhady H. \& Hatch E. 1982. Research Design and Statisticsfor Applied Linguistics. U.S.A: Newburry House Publishers,Inc.

Hatch E. \& Lazaraton A. 1991. The Research Manual. Design and Statistics for Applied Linguistics. Massachusets: Heinle \& Heinle Publishers.

Jefferson T, Alderson P, Wager E, Davidoff F. Effects of editorial peer review: a systematic review. JAMA 2002;287:2784-6. 15 September 2008. http://www.greenjournal.org/cgi/content/full/108/4/979

Jefferson TO, Alderson P, Davidoff F, Wager E. Editorial peer-review for improving the quality of reports of biomedical studies (Cochrane Review). In: The Cochrane Library, Issue 2, 2005. Oxford: Update Software.

Karegianes. Myra L. "The Effects of Peer Editing on the Writing Proficiency of LowAchieving Tenth Grade Students." Journal of Educational Research, Vol. 73 (1980). 26 Oktober 2008. http://www.questia.com/PM.qst?a=o\&se=gglsc\&d=76954488 -

Kronick DA. Peer-review in 18th-Century Scientific Journalism. JAMA. 1990;263:13211322. http://jama.ama-assn.org/cgi/content/full/287/21/2784 
McNeal. Ann. Peer-editing students' papers. School of Natural Science. Hampshire College. Amherst MA 01002. 12 Oktober 2008.

http://helios.hampshire.edu/ apmNS/design/RESOURCES/PEER_ED.html - 9k -

Overbeke J. The state of the evidence: what we know and what we don't know about journal peer review. In: Godlee F, Jefferson T, eds. Peer Review in Health Sciences. London, England: BMJ Books; 1999:32-45.

Pierie JP, Walvoort HC, Overbeke AJ. Reader evaluation of effect of peer review and editing on quality of articles in the Nederlands Tijdschrift voor Geneeskunde. Lancet 1996;348:1480-3.[Medline]

Sugiono, Prof.DR. 2009. Statistika untuk Penelitian. Bandung: Alfabeta.

Tom Jefferson, MD; Philip Alderson, MBChB; Elizabeth Wager, MA; Frank Davidoff, MD. "Effects of Editorial Peer Review. A Systematic Review." JAMA. 2002. 2 Oktober 2008. http://jama.ama-assn.org/cgi/content/full/287/21/2784 